\title{
Smolder Spread in a Horizontal Layer of Cellulosic Powder
}

\author{
KENJI SATO and SETSUKO SEGA \\ Department of Physics \\ Faculty of Science \\ Toho University \\ Funabashi, Chiba 274, Japan
}

\section{ABSTRACT}

Smolder spread experiments for a thin horizontal cellulosic powder bed of high bulk density were conducted with an air stream over the bed. In the experiments, achievement of a two-dimensional structure of the smolder zone was attempted, and spread rate, cross-sectional views, and temperature profiles of the smolder zone were examined. It was observed that for forward smolder spread as the air stream velocity increases, the dependence of the spread rate on the air stream velocity increases at first, but above a critical air stream velocity the spread rate becomes almost independent of the air stream velocity and ultimately complete extinction of the smolder zone occurs. This variation is closely related with the variation of the structure of the smolder zone as seen in crosssectional views. From the comparison of experimental data, it is inferred that the heat balance around the intersection between the exposed, inclined surface of the char oxidation zone and the top surface of the virgin part of the bed is very important to the smolder spread behavior in a thin and high density fuel layer. The aerodynamic effects in the boundary layer over the smolder zone surface control the spread behavior through heat transfer processes.

Key Words: cellulosic materials, powder, spread rate, smoldering, temperature profiles.

\section{INTRODUCTION}

When a smolder zone is once initiated it often survives under surprisingly varied conditions for a long period by adjusting its structure to these conditions. Thus, many studies have been concerned with elucidating the limits and behavior of smolder spread[1-6].

One of the most important and typical configurations in which unwanted smolder spread occurs is a horizontal layer of fuel, and studies on such layers have been conducted for various fuels $[1,2,4-6]$. In these studies, the effects of an air stream over the layer on the behavior of the smolder spread have been emphasized. Ohlemiller's recent series of studies elucidated in detail the effects of the air flow on smolder spread in a relatively thick layer of loosely-packed cellulosic insulation that simulated the conditions in an attic space $[5,6]$. 
In spite of the efforts in these studies, the relation between thr results from different studies has not been so clearly understood an this makes it difficult to predict smolder behavior for other, differen. conditions. The deficiency in understanding may be due both to complicated, combined effects of many physical or chemical factors on smolde spread and a shortage of appropriate experimental data to compare the mechanisms that dominate each smolder spread behavior.

In the present study, in order to provide new information about smolder spread in a horizontal fuel layer, experiments were conducted or smolder spread in a thin bed of cellulosic powder with an air stream over the bed. To obtain basic information, the achievement of a two-dimensional structure of the smolder zone was attempted. In the experiments spread rate, cross-sectional views, and temperature profiles of the smolder zone were examined. Based on the results, the controlling mechanisms of smolder spread in a horizontal layer are discussed from a consideration of heat transfer and aerodynamic effects.

\section{EXPERIMENT}

Experiments were conducted in 15-cm-long horizontal rectangular duct having a $3 \mathrm{~cm} \times 10 \mathrm{~cm}$ cross section. A bed of cellulosic powder having $\varepsilon$ straight rectangular cross section was placed on the bottom surface of the duct. The duct was installed at the exit of the converging nozzle of a wind tunnel(Fig. 1). The air stream was supplied from a blower through an orifice, a settling chamber containing 5 damping screens of 100 mesh. The bottom part of the duct was a 1.5-cm-thick glass wool board. The surface of the board was made flush with the exit of the converging nozzle and covered by a thin aluminum film(15 $\mu \mathrm{m}$ in thickness) to facilitate easy cleaning of the residue that adhered during an experimental run.

After some preliminary experiments, it was shown that if the side of the powder bed touches the wall of the duct the smolder zone at the side is weakened or quenched by large heat losses and a two-dimensional structure is not achieved. Further, it was found that a narrow air gaf between the bed and the wall is effective to control the local smolder spread rate at the side so as to keep a straight leading edge of the smolder zone with negligibly small disturbance to the main burning part for a substantial range of air stream velocity. Thereafter the gap was

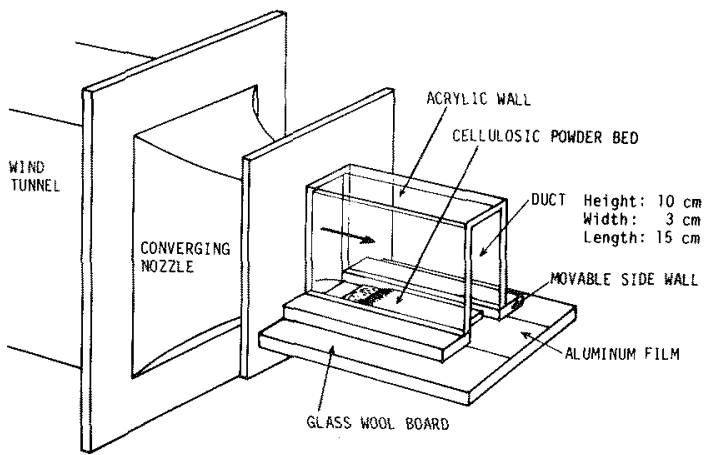

FIGURE 1. Experimental apparatus. 
used to achieve a two-dimensional structure. The width of the bed was $2.7 \mathrm{~cm}$. In order to control the smolder spread rate at the side properly, the lower part of the side wall of the duct was made movable and the width of the gap on each side was slightly adjusted around $0.15 \mathrm{~cm}$ (the remaining upper part of the side wall and the top wall formed a one piece acrylic window for observing the burning zone). The thickness and length of the bed were 0.4 to $1.0 \mathrm{~cm}$ and $11 \mathrm{~cm}$, respectively.

The cellulosic powder used as fuel was made by mixing pure cellulose powder(200-300 mesh), which does not smolder in air, and fine powder of Machilus Thunbergii which promotes smoldering and is widely used in incense sticks. The weight fraction of the Machilus Thunbergii powder was $15 \%$ and the bulk density of the bed was $0.463 \mathrm{~g} / \mathrm{cm}^{3}$.

The mixed powder was packed uniformly into a mold placed on the glass wool board, and after the powder bed was formed the mold was removed. The upstream or downstream end of the bed was heated up by a small flame until a self-sustained smolder zone was formed uniformly across the whole width. During heating up, the air stream over the layer was blocked to permit it to ignite easily. The heat-up time for ignition was about thirty seconds. After the flame was removed, the upper part of the duct was installed and the bed was exposed to the air stream.

The rate of smolder spread was determined as the horizontal spread rate of the leading edge of the char oxidation zone. A view of a vertical cross section of the smolder zone was obtained by cutting the bed with a sharp knife. The temperature of the bed was measured by using two alumel-chromel thermocouples (wire diam. $50 \mu \mathrm{m}$ ) with the junctions at the center of the width. One of them was set at a fixed height and the other at the bottom of the bed as a reference. From superposition of the temperature-time diagrams at different heights, the temperature profiles in the smolder zone were determined.

\section{RESULTS AND DISCUSSION}

\section{Spreading Smolder Zone}

Figures 2 and 3 represent the dependence of the spread rate $V$ of the smolder zone on the free-stream velocity $u_{\infty}$ and typical views of the cross section of the smolder zone, respectively. $V$ was determined as the mean value of the spread rate over a $4 \mathrm{~cm}$ length starting from a position $3.5 \mathrm{~cm}$ from the ignited end. $u_{\infty}$ represents the free-stream velocity at the exit plane of the converging nozzle. The bed thickness $h$ is $0.8 \mathrm{~cm}$.

When the air stream and smolder spread move in the same direction $\left(u_{\infty}>0\right)$, so-called forward smolder[6] occurs. In the forward smolder the dependence of $V$ on $u_{\infty}$ changed with $u_{\infty}$, being closely related to the variation of the structure of the smolder zone with $u_{\infty}$. When the downstream of the bed is ignited $\left(u_{\infty}<0\right)$, so-called reverse smolder occurs (Region V). In this study, the reverse smolder was not pursued in any further detail because of the large, undesirable effect at the sides.

In the range of $0<u_{\infty}<2 \mathrm{~m} / \mathrm{s}$ (indicated as Region $\mathrm{I}$ ), smolder spread is essentially steady except during the 2 or $3 \mathrm{~cm}$ of movement from the ignited end, and $V$ increases gradually with $u_{\infty}$. In this region, a light ash covers the bed from the leading edge of the char oxidation zone back to the ignited end. A thick layer of carbonized black residue plus 


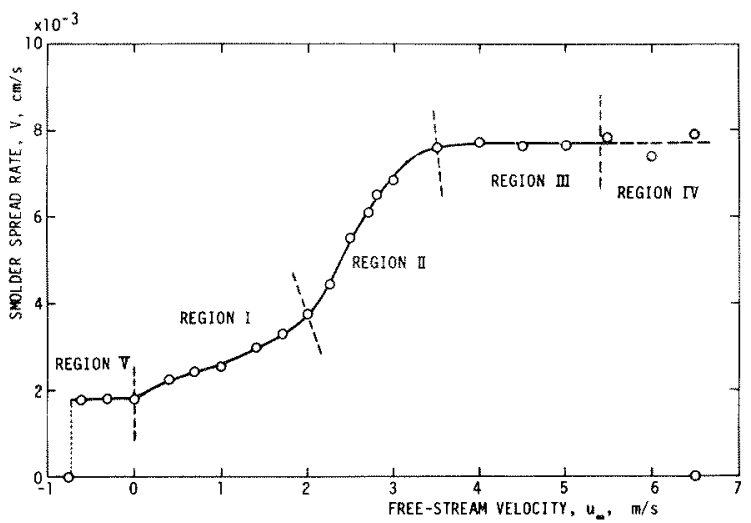

FIGURE 2. Dependence of the spread rate $V$ of the smolder zone on the free-stream veloeity $u_{\infty}$. Bed thickness $h=0.8 \mathrm{~cm}$.

a partially pyrolyzed or unburned layer are left after the passage of the burning zone. When $u_{\infty}$ is very small, quenching occurs at the sides.

When $u_{\infty}$ is $2 \leq u_{\infty}<3.5 \mathrm{~m} / \mathrm{s}$ (Region II), most of the ash is removec by the air stream, and a moderately inclined surface of the char oxidation zone is exposed to the air stream directly or through a very thir ash layer. The inclined surface is wide and almost flat. In this case, $V$ increases steeply with $u_{\infty}$, while the angle between the char oxidation zone surface and horizontal was observed to be nearly independent of $u_{\infty}$.

Above $u_{\infty} \simeq 3.5 \mathrm{~m} / \mathrm{s}$, in contrast with Region II, $V$ is almost independent of $u_{\infty}$ (Region III). Around $u_{\infty} \simeq 3.5 \mathrm{~m} / \mathrm{s}$ the angle of char oxidation zone becomes very large, and its value increases gradually with $u_{\infty}$. In this case, local extinction of a short length of the upper part of the bed appears periodically at the leading edge of the char oxidation zone surface, i.e., at the intersection between the char oxidation zone surface and the horizontal, top surface of the bed. This leads to a local overhang of short length. The overhang grows with time and finally it is consumed rapidly as a hot spot. In Region III, this local extinction is not so serious and overall two-dimensionality is essentially retained; the local spread rate is essentially constant during a run.

At much higher $u_{\infty}$, indicated as Region IV, serious overhang phenomena occur frequently. The dimension of each overhang is large and most of the overhangs fold down yielding a crack at the top surface so that the local spread rate fluctuates with time and the overall value of $V$ shows scatter. This sequence leads to a large deviation from a two-dimensional, stable structure, and often to complete extinction.

The minimum depth(thickness) for smolder spread and $V$ for different values of $h$ were examined with $u_{\infty}$ fixed at $2.8 \mathrm{~m} / \mathrm{s}$. The minimum deptr. was about $0.4 \mathrm{~cm}$. $V$ decreased with $h$ at a rate of $-4.2 \times 10^{-3} \mathrm{~cm} / \mathrm{s} / \mathrm{cm}$. The cross-sectional view was almost the same as that of Region II, except near the minimum depth where the view was that of Region III or IV. AIthough in some previous studies of horizontal fuel layers the occurrence of a transition to flaming or of temporary flaming during smolder has been reported $[1,2,4,6]$, throughout this study these were not observed. 


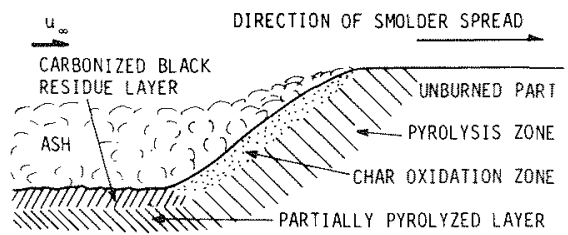

IIIIIIIII!ा

(a) REGION I

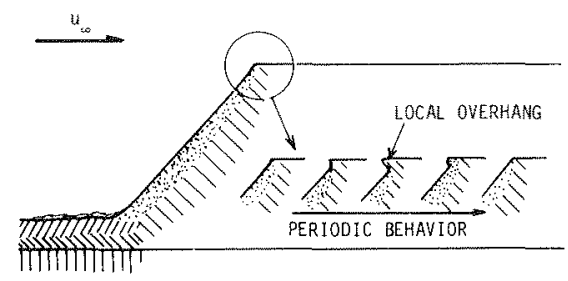

(c) REGION WII

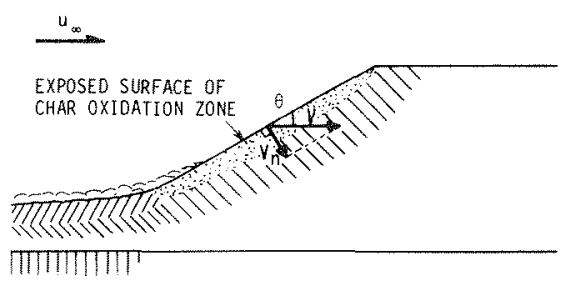

(b) REGION II

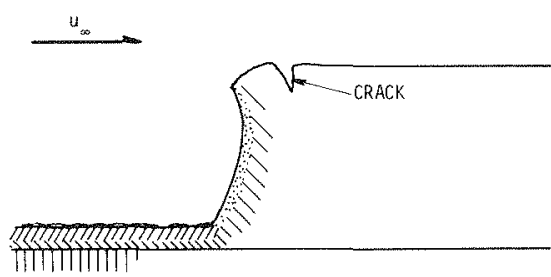

(d) REGION N

FIGURE 3. Typical cross-sectional views of the spreading smolder zone.

Temperature Profiles in the Smolder Zone

Typical temperature profiles in the smolder zone were determined for Regions I, II, and III(Fig. 4). The junction of the thermocouple was set at $6 \mathrm{~cm}$ downstream from the ignited end. $h$ is $0.8 \mathrm{~cm}$. $x$ and $y$ are the horizontal distance from the leading edge of the char oxidation zone surface and the vertical distance from the bottom of the bed, respectively.

Figure $4(a)$ is an example in Region $I$. The dashed lines represent isotherms in the ash. The maximum temperature is attained near the leading edge of the char oxidation zone. In the unburned part, far from the reaction zone, the temperature at the top rises much faster than that of the lower part. On the bottom of the bed the $100^{\circ} \mathrm{C}$ isotherm runs slightly ahead, compared to the region slightly higher. This might be caused by heat conduction through the thin aluminum film. The temperature gradients in the ash layer and those in the other part in the smolder zone are almost of the same order.

Figure 4(b) represents typical profiles in Region II. The maximum temperature increases. The isotherms near the char oxidation zone surface are essentially parallel except near the lower end. The temperature gradient normal to the isotherms is larger than that in Region $I$. In the preheat zone far from the char oxidation zone, the temperature at the top surface rises faster, like the previous case.

Figure 4(c) represents an example in Region III. Though in this region the local overhang occurs periodically, the data used to produce the figure are chosen to express the profils at the instant when an overhang has not formed. The maximum temperature is higher than in the previous cases and the temperature gradient is also larger. In the vicinity of the leading edge of the char oxidation zone surface, the isotherms are almost vertical and the temperature gradient is significantly larger than elsewhere. The top of the $100^{\circ} \mathrm{C}$ isotherm does not extend so much downstream toward the unburned part. 


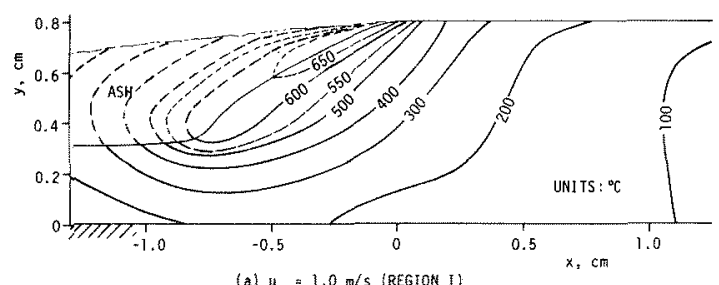

(a) $u_{\infty}=1.0 \mathrm{~m} / \mathrm{s}$ (REGIOH I)

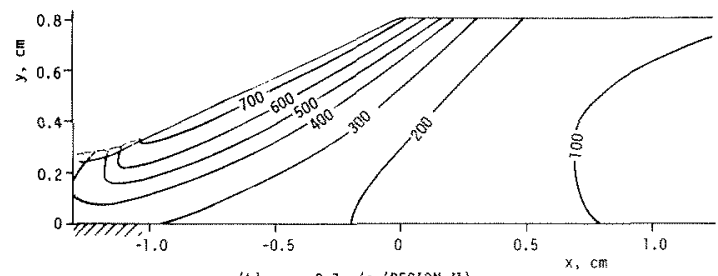

(b) $u_{\infty}=2.7 \mathrm{~m} / \mathrm{s}$ \{Rraton in

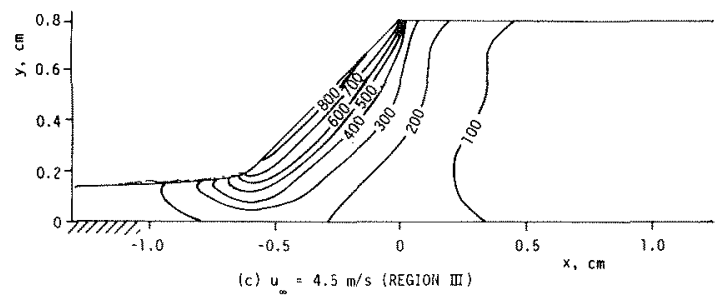

FIGURE 4. Typical temperature profiles in the spreading smolder zone. $\mathrm{x}$ horizontal distance from the leading edge of the char oxidation zone sur. face, $y$ : vertical distance from the bottom of the bed.

Figure 5 shows the distribution of the peak temperature $\mathrm{T}_{\mathrm{p}}$ attainer at each height in the bed, corresponding to the cases in Fig. 4 . From comparison of the three cases, some features of the burning zone becom more evident. It is easily seen that the height where the maximum tem. perature of the smolder zone is attained changes. In Region III, Ip il the vicinity of the top is much lower than that in deeper part in the bet

\section{Controlling Mechanisms of Smolder Spread}

In smoldering, the heat is primarily released by heterogeneous char oxidation zone reaction, and the transfer of released heat to thi unburned fuel part raises its temperature, yielding the pyrolysis reac. tion that produces a new char. Therefore, the aspects of heat transfe: and of oxygen supply at the burning zone are considered to influence thi structure and behavior of the smolder zone.

In Region I, a thick ash layer covers the char oxidation zone. I. acts as a thermal insulator while it also produces a large drag on the air flow approaching the char oxidation zone. These effects may product the weak dependence of $V$ on $u_{\infty}$ as shown in Fig. 2. From the isotherms ij Fig. $4(a)$, it is seen that $\stackrel{\infty}{a}$ large part of the released heat is lost $t$ the base. This heat loss reduces the temperature of the lower part o1 the bed and therefore may cause the thick carbonized or unburned layer. 


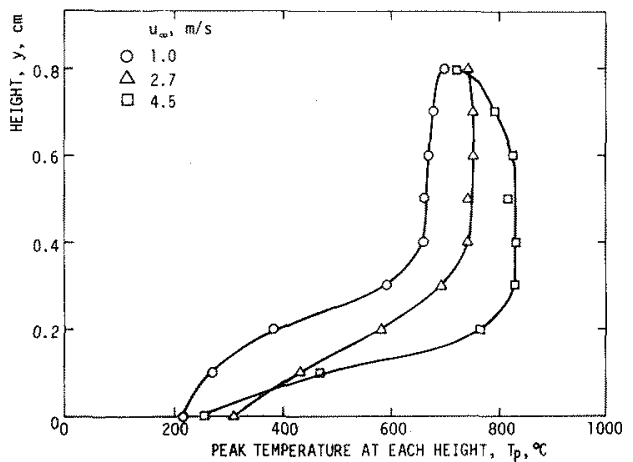

FIGURE 5. Distribution of the peak temperarure $\mathrm{Tp}$ attained at each height in the bed. $h=0.8 \mathrm{~cm}$.

In Region II, most of the inclined, flat, char oxidation zone surface is exposed to the air stream. Thus, compared with the case of Region I, at the char oxidation zone surface, the rate of oxygen supply is much increased while the heat flux to the gas phase and radiative heat loss to the surroundings from the char oxidation zone surface is also increased. In general, when an inclined, thin reaction zone spreads with a constant spread rate $V$ of the leading edge without changing its configuration, any part of the inclined surface must satisfy $V=V_{n} / \sin \theta(F i g . \quad 3(b))$. Here, $V_{n}$ is the normal regression rate of the inclined surface at a fixed point on the surface, and $\theta$ is the angle between horizontal and the surface there. Thus, the flat, char oxidation zone surface means that $V_{n}$ is almost constant over the surface. This uniformity of $v_{n}$ must be related to the observed constant temperature distribution along the surface[7]. The constant temperature distribution is expected to be produced as follows. Due to the oxygen consumption by char oxidation reaction, the gradient of oxygen concentration in the gas phase normal to the surface decreases along the air stream direction, yielding the decrease of the local heat release rate. At the same time, the development of the thermal boundary layer decreases the local heat flux from the char oxidation zone surface to the gas phase along the flow direction. The coupled effect of them may produce the nearly uniform surface temperature.

The relation between $V, V_{n}$, and $\theta$ indicates that in Region II a set of $V_{n}$ and $\theta$ determines the value of $V$. Therefore, the mechanisms to determine the values of $V_{n}$ and $\theta$ are important. $V_{n}$ is considered to be related to the oxygen supply rate to the char oxidation zone. From the consideration of the boundary layer theory it may be said that the oxygen supply rate to a fixed point on the surface is approximately proportional to $u_{\infty} 1 / 2$ in case of laminar flow, since the observed angle $\theta$ is independent of $u_{\infty}$. However, the estimated dependence of $v_{n}$ on $u_{\infty}$ is much greater. A similar discrepanoy was also reported in Ref. [6]. The rapid increase of $V_{n}$ may be also related to the changes of heat balance at the surface and reaction scheme, or to velocity fluctuations induced by the rough surface upstream of the inclined surface via transfer processes. At present, the reason of the rapid increase of $V_{n}$ is not clear.

The mechanisms which control the value of $\theta$ are considered from the heat balance at the horizontal, top surface of the bed. The expected thermal structures in Regions II and III are schematically ilIustrated in 


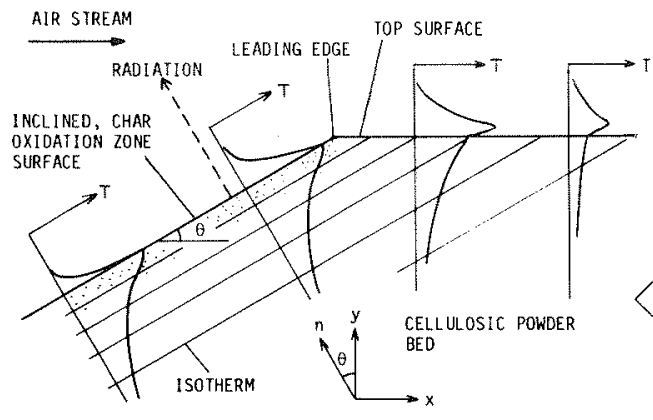

(a) REGION II

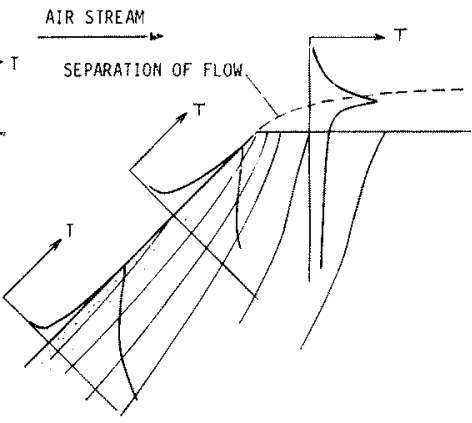

(b) REGION II

FIGURE 6. Schematic illustrations of expected thermal structure.

Fig. 6 for the aid in discussing these mechanisms. The temperature at the top surface decreases from the edge toward the unburned part. Thus, it may be said that the effects of radiation and reaction at the top surfact on the heat balance may not be so large except very short length. Thus: when the isotherms in the bed remain essentially parallel up to the tor surface near the leading edge, like in Region II, the local, conductive heat input from the gas phase through the top surface must approximately balance $\lambda_{\mathrm{b}}(\partial \mathrm{T} / \partial \mathrm{y})=\lambda_{\mathrm{b}}(\partial \mathrm{T} / \partial \mathrm{n}) \cos \theta$ in the bed to keep the straight isotherms. Here, $n$ is the distance normal to the char oxidation zone surface, and $\lambda_{b}$ is the thermal conductivity in the bed. Figure 7 show examples of the distribution of $(\partial \mathrm{T} / \partial \mathrm{y})$ in the bed along the top aheac of the char oxidation zone estimated from the temperature profiles. $\theta$ is controlled to achieve the optimum condition where the isotherms are kepi flat and $V$ is constant[7]. The gradient ( $\partial \mathrm{T} / \partial \mathrm{y}$ ) of the gas-phase temperature at the top surface depends mainly on the temperature profiles ir the boundary layer at the leading edge of the char oxidation zone anc locally on the decay of the thermal boundary layer at the top surface.

Based on the above idea, the effect of $u_{\infty}$ on the smolder behavion in Region II would be expected. As $u_{\infty}$ is increased, the gas-phase temperature gradient at the top surface in the vicinity of the edge mas be increased by an increase of the convective heat flux in the boundary layer at the edge or by the decrease of boundary layer thickness. At the same time the increase of $u_{\infty}$ may cause a rapid decay of the peak temperature in the boundary layer over the top. Accordingly, when $u_{\infty}$ is in. creased, the heat flux from gas phase to the bed through the top surfact is locally enhanced, being confined within a shorter length. By sucl mechanisms, without changing $\theta$, the change in the heat flux distributior from gas-phase to the top with the increase of $u_{\infty}$ would smoothly matcl the increase of $|(\partial \mathrm{T} / \partial \mathrm{n})|$ in the bed which is produced by increased $V_{n}$.

In Region III, $V$ is almost independent of $u_{\infty}$. However, the estimated $V_{n}$ in Region III is much larger than that of Region II $\left(e . g ., V_{n}=\right.$ $2.6 \times 10^{-3} \mathrm{~cm} / \mathrm{s}$ for $u_{\infty}=2.7 \mathrm{~m} / \mathrm{s}, 5.5 \times 10^{-3} \mathrm{~cm} / \mathrm{s}$ for $\left.u_{\infty}=4.5 \mathrm{~m} / \mathrm{s}\right)$. This means the oxygen supply rate still increases the reaction rate ever in Region III. It is seen from Fig. 7 that in Region III the heat inpui from gas phase to the top is remarkably small compared with that ir Region II. Such a drastic reduction must be connected to flow separatior at the leading edge of the char oxidation zone surface, because separa. tion is accompanied by a recirculation zone that reduces the heat trans- 


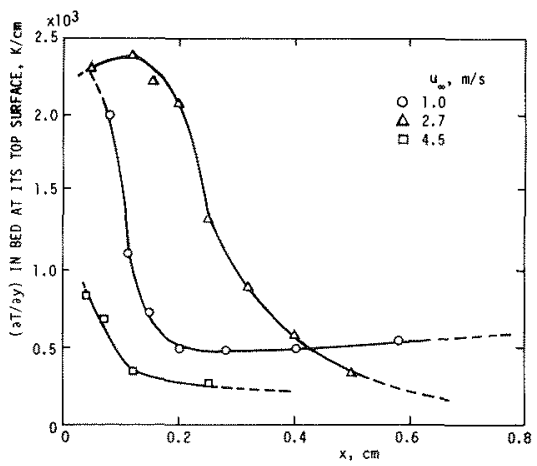

FIGURE 7. Distribution of vertical component ( $\mathrm{T} / \partial \mathrm{y}$ ) of the temperature gradient in the bed at its top surface. $h=0.8 \mathrm{~cm}$.

fer over a wide distance(Fig. 6(b)). Unfortunately, the separation could not be confirmed by eye because the smoke was not visible near the edge.

As mentioned before, a periodic overhang occurred in Region III. Now consider the heat balance near the leading edge in this case. When a large reduction of heat input or cooling at the top occurs, $V_{n}$ and the temperature in the vicinity of the leading edge are decreased. Then, this part is decelerated relatively to the remainder part of the char oxidation zone surface, forcing $\theta$ to increase and also causing the overhang. When the overhang grows beyond a certain dimension, it burns rapidy as a hot spot due to accumulation of the heat from the char oxidation zone below it. The heat release by the hot spot provides a large heat flux to adjacent unburned part and may temporarily strengthen around i.t. By such a sequence of variations of the heat balance around the leading edge, overall steady spread behavior may be maintained.

It is evident from the above discussion that flow separation plays an important role. Two cases are considered as the cause of the appearance of separation. The first is a pure fluid dynamic effect, i.e., the increase in the Reynolds Number. The second is originally based on the failure of the heat supply at the top surface. In the latter, the outline is considered as follows. As a critical value of $u_{\infty}$ is approached, the effects of the factors(at least one of them) which enhance the heat input at the top cannot contribute sufficiently so that $\theta$ begins to move to larger values. $\theta$ moves until the necessary heat flux through the top surface drops more sharply with the increase in $\theta$, passing the condition of the appearance of separation. Although two possible causes are indicated here, at present the actual cause cannot be specified in detail.

When the burning zone is unstable at high $u_{\infty}$, as in Region IV, the heat loss effect at the bottom is relatively small while at the top surface heat input is much reduced or cooling is occurred. This may produce a concave char oxidation zone surface resulting in a divergence of the heat flow to the preheat zone, often, in complete extinction.

In the experiments of this study no flaming was observed in spite of relatively high surface temperatures. The main reason is expected to be that the char oxidation zone surface was too short to accumulate sufficient combustible gases or heat in the boundary layer. 
The discussion here was qualitative and somewhat simplified. How. ever, the essence of it is considered useful as an aid in predicting smolder spread behavior in thin and high bulk density fuel layers anc also in comparing the effects of physical properties on smolder spread.

\section{CONCLUSIONS}

Smolder spread experiments for a thin horizontal cellulosic powdel bed of high bulk density were conducted with an air stream over the bec surface; spread rate, cross-sectional profiles, and temperature profile: of the smolder zone were examined. It was observed that for forware smolder both the dependence of the spread rate on the air stream velocity and the structure of the smolder zone vary with the air stream velocity: being closely related to each other. From the comparison of the obtainec data, it is inferred that the heat balance around the leading edge of the char oxidation zone surface is important to smolder spread phenomena in : thin and high density fuel layer and that aerodynamic effects in the boundary layer over the smolder zone control the spread behavior througl heat transfer processes.

\section{ACKNOWLEDGMENTS}

The authors are indebted to Miss $\mathrm{H}$. Tanaka and $\mathrm{Mr}$. H. Kawasaki fol their help in obtaining the data on smolder spread. This study wa: supported by the Japanese Association for Fire Science and Engineering and also by the Kajima Foundation's Research Grant.

\section{REFERENCES}

1. Cohen, L. and Luft, N. W., "Combustion of Dust Layers in Still Air,' Fuel, 34: 2, 154-163, 1955.

2. Palmer, K. N., "Smouldering Combustion in Dusts and Fibrous Materials," Combustion and Flame, 1: 2, 129-154, 1957.

3. Moussa, N. A., Toong, T. Y., and Garris, C. A., "Mechanism of Smoldering of Cellulosic Materials," Sixteenth Symposium(International. on Combustion, The Combustion institute, Pittsburgh, pp. 1447-1457: 1977.

4. Leisch, S. O., Kauffman, C. W., and Sichel, M., "Smoldering Combustion in Horizontal Dust Layer, Twentieth Symposium (International) or Combustion, The Combustion Institute, Pittsburgh, pp. 1601-1610, 198

5. Ohlemiller, T. J., "Smoldering Combustion Propagation through a Per. meable Horizontal Fuel Layer," Paper Presented at the Western State Section, Combustion Inst., 1983 Spring Meeting, Pasadena, April 1983.

6. Ohlemiller, T. J., "Forced Smolder Propagation and the Transition to Flaming in Cellulosic Insulation," NBSIR 85-3212, U. S. Department of Commerce, October 1985.

7. Hirano, T., Sato, K., Sato, Y., and Sato, J., "Prediction of Meta. Fire Spread in High Pressure Oxygen," Combustion Science and Technology, 32:1-4, 137-159, 1983. 